\title{
Study of the Socio-psychological and Cultural Adaptation of Migrant Children: Analysis of an Account in a Social Network
}

\begin{abstract}
Child migrants are one of the risk factors of the modern education system in Russia. In addition to the potential problems associated with the cultural differences between the indigenous population and migrants, there is also the problem of "closed" migrants. Often migrants and their families, including second- and third-generation migrants, form isolated communities within which the adaptation and socialization of new migrants and the generation of youth takes place. On the one hand, these groups play the role of "soft adaptation", when migrants and their children are offered the tested models of behavior in the new conditions of life. On the other hand, not all the models proposed by the group can be acceptable by the traditions of the indigenous population, and sometimes they are opposed to the culture and traditions of the host country. Moreover, the views accepted in the group can cause morbid socialization of migrants. Under these conditions, the school has a task of preventing the negative impact of the isolated national groups on the younger generation. The purpose of the study is to analyze the account of migrant children in social networks in order to identify signs of socio-psychological and cultural adaptation, to determine the influence of national groups and communities in social networks on the formation of a person's personality. The paper covers the reactions of children to publications on the topic of interethnic communication. It also includes recommendations to teachers on the definition of exposure to the influence of groups and communities in the social networks of migrant children.
\end{abstract}

\section{Keywords:}

migrant children, migrants' adaptation, social networks, recruitment, social activity

1 Kazan Federal University, Kazan, Russia.

CORRESPONDING AUTHOR: Roza Valeeva, E-MAIL: valeykin@yandex.ru 


\section{INTRODUCTION}

One of the main characteristics of the modern information society is the abundance of risk factors in all spheres of human life. Disasters, accidents, death of people occupy a leading place in the information network, and therefore in the minds of people. The role of the human factor in the formation of anthropogenic hazards of techno sphere is increasing in the modern world, characterized by a high level of information technologies and technical means (Devyasilov, 2011).

Activation of risk-bearing factors of the modern educational environment determines the introduction of the noxological component into the structure of teacher's professional competence. Natural (predicted) processes of modernization of the education system are often accompanied by the influence of external factors, which include migrant children, the need to create an inclusive environment, increase in the number of children at risk. Noxological competence is interpreted as an integral personal characteristic of a teacher, which allows predicting and fulfilling professional tasks under risk conditions.

Noxological education is implemented in the Russian education system as part of the training of specialists in the "Life Safety" profile (Devyasilov, 2011; Simakova, 2010). Noxology (from Greek. Noxo - danger) as an independent science "about risks" was developed by a group of Russian scientists led by V.A. Devyasilov. Noxological Studies were devoted to the issues of techno sphere and environmental safety, as well as the issues of training specialists in ensuring safety in the labor and industrial fields. We study in this paper the issues of the socio-psychological and cultural adaptation of migrant children in the framework of the Noxological concept.

The problem of activating migration processes and their influence on the education system is a fairly new phenomenon for modern pedagogical science in Russia. The specificity of traditional-historical relations among the peoples of the former USSR for a long time did not allow to allocate migrants into a separate risk group in the education system. It would seem that migration, including labor one, would be a natural phenomenon in the multinational post-Soviet space. Differences in the culture of nations were compensated by a single history and language. Just as important was the fact of the "atheistic", one-party past. The one party ideology and the denial of religion allowed neutralizing potentially sharp cultural conflicts.

However, since the period of "perestroika" in 1990-2000-s this situation is beginning to change dramatically. Strengthening national identity and gaining autonomy of national republics, increasing the role of religion in human life 
against the background of a general economic and social crisis caused various conflicts, including cross-national ones. Over the past decade, in Russia and the former Soviet Republics, now independent countries, there has been a significant decline in the level of conflicts arising on the basis of interethnic issues. However, the upsurges in the national self-awareness and self-determination of the peoples of the former Soviet Republics, as well as the increasing influence of religion in human life, are currently one of the risk factors in education.

In addition to the potential problems associated with cultural differences between indigenous people and migrants, there is also the issue of "closed" migrants. Often, migrants and their families, including migrants of the second and third generations, form isolated communities in which new migrants and young people are adapted and socialized. On the one hand, these groups play the role of "soft adaptation," when proven models of behavior in new living conditions are offered to migrants and their children. On the other hand, not all models proposed by the group may be acceptable to the traditions of the indigenous population, and sometimes they contradict the culture and traditions of the host country. Moreover, the opinions adopted in the group can cause the painful socialization of migrants. Under these conditions, the school faces the task of forecasting and preventing the negative impact of isolated national groups on the younger generation.

The purpose of this study is to analyze the accounts of migrant children in social networks in order to identify signs of socio-psychological and cultural adaptation; to determine the influence of national groups and communities in social networks on the formation of a personality. The material for our research was the monitoring and analysis of the migrants of different generations account in social networks. Our special attention was paid to the study of children's reactions to publications on the topic of inter-ethnic communication.

The research method is monitoring accounts of migrants of different generations and content analysis of their publications in social networks. Particularly, our attention was focused on the study of children's reactions to publications on the topic of inter-ethnic communication.

The choice of content analysis as the leading method of research is justified by the goals of this method: identifying the focus of individual, group, institutional, and public issues discussed, as well as describing patterns and trends in communicative content, i.e. forecasting information “emissions”. Initially, content analysis was used to analyze media and public speaking. Currently this type of analysis is used to study any form of communication material (Cohen, Morrison \& Morrison, 2011). According to K. Krippendorp (2004) and P. Mayring (2004), content analysis reveals manifest characteristics of communication (who says and 
what, to whom and how), as well as the preceding elements of communication (causes and goals of communication and context communication) and predicts the continuation of communication (its consequences). During the analysis, we identified words-markers used in communication to refer to processes, relationships, and subjects with a certain emotional and expressive characteristic.

The selection of the accounts of respondents for content analysis was carried out using the snowball method. This made it possible to reveal a network of relations between young migrants and individuals belonging to their circle of trust.

During the study, we selected for analysis the pages of young migrants (from 14-20 years old) among the inhabitants of the Republic of Tatarstan. The observation was closed, and fake pages were used for registration in closed groups. We have registered in "ethnic" social groups. By sex, the group studied is a female group. By employment - schoolchildren, students, young single mothers (18 years). The main religion is Islam, the nationality is Azerbaijanis and Uzbeks. We have also revealed "impersonal" pages (through closed groups and comments to publications). The main purpose of the observation was the analysis of personal accounts in social networks and the definition of the main areas of interest and prediction of possible conflicts in this group of respondents.

We have identified marker words used by young migrants in communication to refer to processes, relationships, and subjects of a relatively neutral nature (truth, occupation, neighboring states, Muslim brothers (sisters), the pronoun "we”, ready speech, learned phrases, etc.) and with obvious aggressive emotional and expressive characteristics (terrorist religion, bloody statistics, genocide, etc.)

Markers of the first group are not a direct sign of radicalization. Their meaning is revealed in context. Words like "brothers (sisters)", "we" create a certain close emotional background of communication. For example, "we will endure it ...”.

At the same time, it is necessary to note the frequent use of stylistic methods of opposition, for example, "they are not ... their pain will not become the pain of all mankind", transfer of the amount of funds allocated for armaments and acute social problems. There exist also the problems of the use of automated text analysis systems associated with the abundance of publications in the format of demonstrator and drawings. These publications are perceived by the system as a holistic image, or the drawing is aimed at associative thinking (hidden for mechanical processing, but recognizable text in the drawing). 


\section{THEORETICAL BACKGROUND}

According to S.V. Rzayeva (Rzayeva, 2015), there are few migration studies including theoretical and practical results of the social network studies in the Russian researches, and the network in these works is considered as one of many factors affecting the territorial displacement of the population [8-10].

In determining the ethnic social network, we relied on two key concepts "ethnicity” and "territorial identity”, which is caused by the migrant's belonging to a certain ethnic group and his connection with the territory of departure. Ethnicity provides the internal connection of members of a certain community, outlining the boundaries between "our" and "alien”, being a kind of marker. Ethnicity is a form of social organization of cultural differences, which depends on the context, i.e. it is formed and exists within the social interactions of people. Stressful situations act as a kind of catalyst for the migrant's ethnic identity. The causes of stress can be migration, competition with other groups, solving difficult situations that require the participation of more than one community member. Regarding the concept of "migrants' adaptation", the analysis of various sources suggests that adaptation in the context of migration processes is considered as a component of: 1) migrants' integration; 2) migrants’ social adaptation; 3) migrants' acculturation.

The theory and practice of migrants' adaptation was developed in many studies (Genkova, Trickett, Birman \& Vinokurov, 2014; Wing Yi Chan \& Birman, 2009; Joyce Ho, 2010; Harris, Ravert, \& Sullivan, 2015; Prevoo, Malda, Mesman \& Van IJzendoorn, 2016). They offer different adaptation options for migrants. Ana G. Genkova, Edison J. Trickett, Dina Birman, Andrey Vinokurov (2009), Joyce Ho (2010) propose the acculturation model as the most effective method for migrants to adapt. This model ensures the psychological safety of citizens by adopting the values and culture of the adopted country by migrants. The acculturation model is atypical for the migration policy of the Russian Federation. The policy in the field of interethnic communication of the Russian Federation is based on the preservation and development of the distinctive culture of all peoples living in Russia. This idea is reflected in the works of Russian researchers G.Z. Fahrutdinova (2016), V.F. Gabdulchakov (2016), O.E. Huhlaev (2013). However, issues of the social networks influence on inter-ethnic communication and the personal development of the migrant children are practically not studied.

As already mentioned, migrant children in school are a special area of risk in the education system. At the same time, we highlight the risk for the teacher as an organizer of the educational process and a carrier of special responsibility for the result of education. In addition, it is necessary to highlight the zone of interpersonal 
communication risks for both the migrant child and his classmates. Differences in the culture and traditions of migrants and the host country often cause conflicts in communication and an obstacle in the professional activities of teachers. According to T. Smith, K.Hughes, D.DeJoy, M.-A.Dyal (Smith et al., 2018), frequent and unresolved conflicts cause changes in the personal characteristics of participants in conflict and stress situations. Under the influence of risk factors there is a deformation of the personality. If stress and risks become a permanent characteristic of the profession, it can cause professional deformation. Scientists cite examples of the formation of emotional exhaustion, cynicism, and the depersonalization of the personality of specialists, which leads to ignoring security requirements. The presence of these qualities becomes the cause of conflicts of relations of the individual - family, family - work. The stable forms of these qualities, which have not been eliminated, lead to the professional disadaptation of specialists (Smith et al., 2018).

Revealing the nature of the conflict and ways of resolving it, representatives of social psychology E. Aronson, T. Wilson, R. Ekert (Aronson, Wilson \& Akert, 2015) view conflict as a natural consequence of human intercourse. They note the special role of communication in conflict resolution. Communication will not be effective in resolving the conflict, if there is no initial installation among the participants in the dispute. According to the named researchers, communication in conflict situations is used only for intimidation and threats. The exit from conflict situations is possible through negotiations and search for an integrative solution.

A special medium of communication in modern world is the so-called "Life in the network.” According to R.S. Selezenev \& E.I. Skripak (Selezen \& Skripak, 2013) modern society is experiencing the effect of a kind of compression and close communication via the Internet thanks to the development of new information technologies. The close interaction between people through the Internet space F. Fukuyama calls simply the "network" which is a moral connection based on trust (Fukuyama, 1999). A group of Russian anthropologists note the development of parallel life in the network noting that there is a quasi-life and thinking beings in this digital reality, and this reality depends on the thinking beings (Toiskin, Shumakova \& Krasilnikov, 2012). Defining the special role of the information space, L. Grossman (1995) believed that the third big stage in the development of democracy comes through the use of new technical means. And this is the a hybrid "electronic republic", replacing the America's long-standing structure of representative government.

Online communication has some unique properties that live communication can't boast. These include: 
- anonymity - no one person can reveal anywhere as much as possible on the Internet. At the same time, the user himself determines how much he is ready to open up to one or another interlocutor, what character traits he would like to show, and what to hide, and, not least, the person regulates the duration of his communication, giving him exactly as much time as he can afford;

- a huge audience of potential interlocutors. Only through the Internet can one communicate with people whom a person has never seen before, and may never see;

- the opportunity to find not only close friends of interest, but also a life partner, if lucky.

These characteristics of online communication today have already become the reason for the preference of the younger generation of online communication to offline communication ("live"). For this reason, we chose communication in the modern information space - in the form of personal accounts on social networks VKontakte and Instagram - the main object of our study.

\section{DEVELOPMENT OF THE SAFE INFORMATION SOCIETY}

From the standpoint of legal security, one of the areas of implementation of the Strategy for the development of the information society in the Russian Federation is to counter the use of the potential of information and telecommunication technologies in order to threaten Russia's national interests. However, a weak legislative base and even weaker compliance allows the Web to have virtual extremist communities to involve new members in their ranks, the bulk of whom are young. The Sarnoff's law states that "the value of a broadcast network is directly proportional to the number of viewers" (Sarnoff, 1968). However, in the youth environment the point of criminal responsibility is missing. On 14/09/2018, a number of bills from the so-called Yarovaya Package, including the Federal Law of 27.07.2006 N 149-FZ (as amended on July 19, 2018) “On Information, Information Technologies and Protection of Information” came into force ${ }^{2}$. A number of documents provide for the responsibility for the distribution and publication of information. For example, according to the document, bloggers who have at least 3 thousand visits per day on their personal website or page will be entered into a certain registry and

2 Federal Law of July 27, 2006 No. 149-Ф3 (as amended on July 19, 2018) “On Information, Information Technologies and Information Protection”. http://legalacts.ru/doc/FZ-ob-informaciiinformacionnyh-tehnologijah-i-o-zawite-informacii/. 
will be able, in particular, to accept advertising on a fee-based basis. In our case, this illustrates the dangerous desire of young people to hype (to become famous in something and anywhere, to create a sensation) through scandalous publications on the network ignoring of the consequences of these actions. In social networks there is a definite tendency to increase the number of subscribers. In the information block of VK (https://vk.com) it says so:

1000 subscribers - your page starts to appear in the block "Interesting pages" of your subscribers. In this list, user pages are located after all the communities, therefore you should not count on a large influx of the audience through this channel. 10,000 followers - your recent website statistics on posts: likes, reposts, comments, traffic becomes available to your profile. (What influences..., 2018)

As a rule, members of virtual communities in a social network are teenagers. In adolescence very important personal qualities begin to form: the desire for development and self-awareness, interest in one's own personality and its potentials, ability to self-observe. The key features of this period are the reflection and the formation of moral convictions. Adolescents are beginning to realize themselves as a part of society and acquire new socially significant positions, make attempts of self-determination. That is why it is extremely important to protect the mind of a teenager from the impact of social media promoting violence and xenophobia. Extremism (from the Latin. Extremus 'extreme') in modern science is commonly understood as the commitment of social actors to extreme views and measures (Antonova, 2012).

The Russian scientist S.K. Tamazyan believes that "the other side of" networking "was the emergence of new types and ways of social interactions between individuals and social groups, characterized, among other things, by socially dangerous manifestations. These manifestations are expressed in the absence of a system of sanctions and control over the dissemination of any type of Internet information, difficulties in identifying ideologues and leaders of extremist and separatist associations who also conduct their activities using social networks and in many other things " (Tamazian, 2012, p. 3).

\section{RESULTS}

In the course of the study, we identified dangerous groups among the subscribers. By the nature of the publications and the work carried out, these groups can be divided into: 
1) outright provocation groups - materials of extremist content are published, often "closed", publications are rudely oppressive, aimed at harsh suppression of "a different opinion", there are "mirrored" pairs in case of closure;

2) groups with hidden, implicit provocation - informational materials are published, often the style of the publication is popular science, the "open" group.

More dangerous in this case is the second type of group. Identification of such groups takes more time, as there are difficulties in proving the content of materials of extremist type. For example, public groups, one way or another devoted to the topic of Nagorno-Karabakh. The published material is of general informational nature, the texts are often in the Azerbaijani language, aimed at an audience of 14 to 25 years. A detailed study of the structure of the group (links, reposts, group administrators) reveals a connection with groups of the first type. Thus, groups of the second type are a kind of gateway, a mediator for attracting and activating the "risk" group among the youth of this nationality, migrants, "sympathizers". The analysis revealed one of the basic technologies for the development of the necessary topic, from informational publication to publication with a call to extremist actions. For example, we present publications on the problem of the oppression of Muslims in Myanmar. After the publication, in a certain period of time, posts appeared about the situation in Myanmar in 2017 in groups of the second type. The essence of the publication is informing and expressing condolences to the relatives of those killed and injured in the conflict. Each publication was accompanied by an illustration in the form of an infographic, a photo, or a drawing of a demonstrator type. In parallel, in groups of the first type, posts appeared with harsh criticism of the actions of government forces in conflict, neighboring states and states with a certain percentage of the Muslim population, including Russia. These countries and/or their Muslim inhabitants were accused of inaction. Analysis of likes and reposts of these records allows concluding that these posts were mostly "heard" by young people from 14 to 25 years old. Next, we want to draw attention to the problem of the reliability of materials published on the topic of the conflict in Myanmar. The user Masterok writes in livejournal ${ }^{3}$ that the authors of the posts on the topic of the 2017 Myanmar conflict were extremely aggressive and rude. He provides a comparative analysis of the most frequent illustrative material on this topic. He makes a conclusion that $80-90 \%$ of these publications are falsifications. These publication-revelations allow young readers to see an alternative reality. 
However, this kind of work is often blocked in more readable social networks VK and Facebook or are met with active criticism from users.

Analyzing users of social networks, S.K. Tamazyan gives the following typology of community members:

1) provocateurs exposes (founders of groups, initiators, nationalists),

2) the witnesses (those who previously did not have a special relationship to this problem, but were influenced by the moderators of the groups),

3) trolls,

4) antipode provocateurs (protectors, exposers).

The following observation seems interesting: the moderator of the group has the right to remove/block any member of the group, including the "alien”, but in practice he does not use this right of the censor. It can be assumed that such groups need "dissent". Their existence allows the group to develop, its founders and active participants - to discuss publicly and test their "theories".

Within the framework of the study, the respondent's "inner circle" was analyzed: his friends, subscribers, and the level of participation in the respondent's virtual life. As T. Opsahl, F. Agneessens, J. Skvoretz (Opsahl, Agneessens, \& Skvoretz, 2010) noted, the subject of communication and its "power" are one of the central themes in the study of social networks. At the same time, the authors recommend determining the "roles" of people who are among friends when studying social networks. There were also identified types of communication on the Web: "direct communication" (correspondence on the Internet, comments on posts) and “indirect” (quotes and statuses, repost, monologic publications).

The analysis allowed identifying a direct relationship between the general emotional and meaningful content of publications on the page and the quantitative and qualitative composition of the respondent's friends. Publications with "sympathetic" content prevail among respondents with an overwhelming majority of friends who are members of national (ethnic) groups in social networks. At the same time, the majority of respondents are in the group of "witnesses", which was expected in principle. This phenomenon indicates the need to strengthen work with this category of youth and children. Especially, it is necessary to pay attention to the personal growth of the respondent and the formation of his legal and inter-ethnic culture. If we turn to the analysis of types of acts of communication, then reposts and likes (approvals) of publications prevail. The predominance of these types of communication also indicates the correspondence of respondents to the group of "witnesses". 
Summing up, it should be noted the positive experience of public and state organizations of the Republic of Tatarstan in combating information manipulation of young migrants. First of all, this work is carried out by the regional branch of the public movement \#Kiberdruzhina, created by the League of the Safe Internet. It brings together more than 20 thousand volunteers from all over Russia and the CIS countries fighting crime in a virtual environment. The main activity is blocking sites, groups in social networks that pose a threat. With the participation of volunteers, law enforcement agencies in Russia and foreign countries have uncovered hundreds of criminal cases involving the dissemination of child pornography, child sexual abuse and other crimes against society and the state.

Despite the high efficiency of this activity, the problem still remains relevant. Moreover, sometimes for various reasons young people and adolescents are themselves the creators and activists of such groups. Thus, the system of education and socialization of the young generation should fulfill the task of forming a personality capable of counteracting information manipulations.

The Youth Assembly of the Peoples of Tatarstan and the Public Organization "Academy of Creative Youth" are working in this direction. The main idea of neutralizing the activities of extremist groups in social networks is the creation of alternative communities for migrant children and young people, filling the information space with revealing, explanatory content.

We recommend that the modern education system take into account the experience of the above-listed organizations in socio-psychological and cultural adaptation of migrant children. According to experts, it is necessary to determine the psychophysiological characteristics of children at risk who were found with publications and reposts of dangerous content and being the members of radical ethnic groups on social networks. For example, the psychologist A.A. Skorodumov (1996) in his study on the disadaptation of the individual as a result of a person's stay in a destructive cult, systematized and compiled the most comprehensive list of opinions of various specialists regarding the possible causes of a person's joining a cult.

The scientist recommends paying attention to the following factors:

1. Egocentrism, narcissism,

2. The desire for mystical experiences and faith in paronormal.

3. Participation in hostilities and stay in extreme situations involving risk to life.

4. The period of adaptation after significant changes in life.

5. Difficulties in communicating with the closest environment and family 
The feeling of loneliness, the fear of the present and the future are pushing the child-migrant to look for alternative and safer from his point of view types of communication in Social Networks. Visible safety dulls the child's natural caution, it becomes open to the interlocutor. Explanation of the attractiveness of such organizations is very simple: recruiters offer a simplified prospect for the future; allow standardizing manners and actions, relieve shyness and self-observation. In addition, collective actions weaken the limitations and feelings of personal guilt. Hence, a person has a seeming harmony of the inner world, filled with good and evil forces, with the outside world and its real goals and dangers.

\section{CONCLUSION}

Attitude to the processes of globalization and the spread of the influence of the Internet will always be ambiguous. We examined in our study the issues of the social networks and media influence on school education and the process of training future teachers. The topic and problem of our study is due to the emergence of special personality changes of young people (the majority of schoolchildren from 10-17 years old), occurring under the influence of Networks. Modern Russian and foreign scientists have identified a number of changes in worldview, value orientations, patterns of behavior of people, which are artificially created and promoted in the form of trends, hype in the information environment. For this reason, this aspect of the information environment is becoming an actual area of noxological research in education.

\section{Acknowledgments}

The work is performed according to the Russian Government Program of Competitive Growth of Kazan Federal University

\section{References}

Antonova Yu. A. (2012). Virtual community in a social network as a way to spread extremist ideology among young people. Political Linguistics, 4 (42), pp. 70-80.

Aronson, E., Wilson, T.D., \& Akert, R.M. (2015). Social Psychology, 9th edition. Boston, MA: Pearson/Allyn and Bacon.

Devyasilov, V.A. (2011). Noxological aspects of education humanization. Higher education in Russia, 1, pp. 129-132.

Chan, W.Y., Birman, D. (2009). Cross-and same-race friendships of Vietnamese immigrant adolescents: A focus on acculturation and school diversity. International Journal of Intercultural Relations, 33 (4), pp. 313-324. 
Cohen, L.L., Morrison, M., Morrison, K. (2011). Research Methods in Education, 7th edition. London: Routledge.

Fakhrutdinova, G. Z. (2016). Ethno-Pedagogical Factor of Polycultural Training. International Journal of Environmental and Science Education, 11(6), pp. 1185-1193.

Fukuyama, F. (1999). The Great Disruption. London: Profile Books.

Gabdulchakov, V.F., Galimova, E.G., \& Yashina, O.V. (2016). The use of problem-based technologies in multicultural education of future teachers. IEJME, 11(4), pp. 755-766.

Genkova, A.G., Trickett, E. J., Birman, D., \& Vinokurov, A. (2014). Acculturation and adjustment of elderly émigrés from the former Soviet Union: A life domains perspective. Psychosocial Intervention, 23(2), pp. 83-93.

Grossman L.K. The Electronic Republic: Reshaping Democracy in America. New York, 1995.

Harris, B., Ravert, R.D., Sullivan, A.L. (2015). Self-Identification of Multiple and “Other” Race/Ethnicities. Urban Education.

Joyce Ho (2010). Acculturation gaps in Vietnamese immigrant families: Impact on family relationships. International Journal of Intercultural Relations, 34(1), pp. 22-33.

Khukhlaev, O.E., Kuznetsov, I.M., Chibisova, M.Yu. (2013). The integration of migrants in the educational environment: social and psychological aspects. Psychological Science and Education, 3, pp. 5-18.

Krippendorp, K. (2004) Content Analysis: An Introduction to its Methodology. Thousand Oaks, CA: Sage.

Ibáńez-Cubillas P., Díaz-Martín C., Pérez-Torregrosa A.B. (2017). Social Networks and Childhood. New Agents of Socialization. Procedia - Social and Behavioral Sciences, 237, pp. 64-69.

Mayring, P. (2004) Qualitative content analysis. In U. Flick, E. von Kardoff \& I. Steinke (eds.). A Companion to Qualitative Research. London: Sage.

Opsahl T., Agneessens F., Skvoretz J. (2010). Node centrality in weighted networks: Generalizing degree and shortest paths. Social Networks, 32 (3), pp. 245-251

Prevoo, M.J.L., Malda, M., Mesman, J., van IJzendoorn, M.H. (2016) Within- and Cross-Language Relations Between Oral Language Proficiency and School Outcomes in Bilingual Children With an Immigrant Background. A Meta-Analytical Study. Review of Educational Research, 86 (1), pp. 237-276.

Rzayeva S.V. (2015). Ethnic social network as a mechanism of migration processes and adaptation of migrants in the host society: the concept and structure. Bulletin of Tomsk State University, 395, pp. 60-66.

Sarnoff, D. (1968). Looking Ahead: The Papers of David Sarnoff. New York: McGraw Hill.

Simakova, E.H. (2010). Developing the noxological competence of technical university students - future professionals in the field of wellness and safety. PhD Thesis. Shuya.

Skorodumov, A.A. (1996). Socio-psychological analysis of personality maladjustment (on the example of modern non-confessional currents). PhD Thesis. St. Petersburg.

Sho Tsugawa, Kazuma Kimura. Identifying influencers from sampled social networks. Physica A: Statistical Mechanics and its Applications, 507, pp. 294-303

Smith, T.D., Hughes, K., DeJoy, D.M., Dyal, M.A. (2018). Assessment of relationships between work stress, work-family conflict, burnout and firefighter safety behavior outcomes. Safety Science, 103, pp. 287-292 
Selezenev R.S., Skripak E.I. (2013) Social networks as a phenomenon of the information society and the specificity of social connections in their environment. Bulletin of Kemerovo State University, pp. 125-130.

Tamazyan, S.K. (2012). Social Interaction in the Unformalized Networks of Modern Russian Adolescents. PhD Thesis. Stavropol.

Toiskin, V.S., Shumakova, A.V., Krasilnikov, V.V. (2012). The anthropological dimension of social Internet services. Stavropol: Publishing house SGPI.

What does the number of subscribers follow? URL: https://vk.com/page-2158488_50443788 